\section{Language in adults with Down syndrome}

\section{Jean A. Rondal and \\ Annick Comblain}

\author{
Laboratoire de Psycholinguistique, \\ Université de Liège, Belgium
}

\begin{abstract}
In this paper, we will try to supply at least a partial answer to the three following questions. First, what language levels are reached by adults with Down syndrome? Second, is there progress in language or some aspects of it beyond adolescence and during the adult years? This question is related to the issue of a critical period for language development raised by Eric Lenneberg (1967). Third, what is the effect of ageing on the language of persons with Down syndrome, including those who develop Alzheimer disease in old age?
\end{abstract}

Paper presented at:

The International Conference on Language and Cognitive Development in Individuals with Down Syndrome, September 1994, University of Portsmouth, Portsmouth, UK.

(C) 1993, 1999. The Down Syndrome Educational Trust Down Syndrome Research and Practice

1996, 4 (1) 3-14
Introduction

The population incidence of Down syndrome has not changed substantially over the last decades. It is approximately 1/750 live births in both sexes (Dolk et al., 1990). Down syndrome is still estimated to be the aetiology of up to $30 \%$ of moderately and severely intellectually impaired individuals. However, life expectancy in Down syndrome has increased dramatically. According to Oliver and Holland (1986), it was 9 years in 1929, 12 to 15 years in 1947, and 18 years in 1961 (with two thirds of the children dead by the age of twelve, Carter, 1958). At present, as many as $70 \%$ of individuals with Down syndrome may expect to live beyond 50 years (Mann and Esiri, 1988), 44\% will survive to the age of 60 years, and $13.1 \%$ to 68 years, compared with $86.4 \%$ and $78.4 \%$, respectively, for the general population, irrespective of sex (Baird and Sadovnick, 1988). As a consequence of this evolution (determined largely by medical progress, enhanced social awareness, within-family rearing, and early and continued quality stimulation and education), it is expected that between the years 1990 and 2010 , the number of persons with Down syndrome over the age of 40 years will increase by $75 \%$, and over 50 years by $200 \%$ (Steffelaar and Evenhuis, 1989).

These are encouraging indications for those who believe in the absolute right of all human beings to live and to develop to their best potentialities. They also make it all the more necessary to gather comprehensive data (medical, psychological, social, etc.) on adults with Down syndrome in order to evaluate more precisely their functioning capacities, the possible evolution of these capacities in time, and to ensure the best possible social, emotional, and vocational adjustment of these individuals. Language may have a particularly important role in these adjustments. Some people (e.g., Swetlik and Brown, 1977) claim that impaired language and communication skills constitute the major impediments to the integration of intellectually impaired citizens in society. More studies of adults with Down syndrome are urgently needed in order to meet the above challenge.

Before reviewing the available data, a word of caution is necessary. First, the data on the language abilities of adults with Down syndrome are still limited and one should be cautious in generalizing any conclusion from these data. Second, a kind of "cohort caveat" is possibly involved in the question at stake. Most adults with Down syndrome as of today, have not benefited from early educative intervention, simply because such programs were not in existence 25 or 30 years ago. Assuming at least minimal long range positive effects from such intervention, it is likely that future adults with Down syndrome will demonstrate higher performance levels (language and otherwise) than present-day adults. It would be a mistake to use the empirical indications available today on the capabilities of adults with Down syndrome as if they were genuine norms of ultimate achievement.

1. Language levels in adults with Down syndrome Comblain (1994) gathered systematic language data in a sample of French-speaking subjects (females and males) from the Liège area, in Belgium. There were 11 children (8 girls, 3 boys) aged 6 years 10 months to 12 years 10 months, 16 adolescents ( 9 girls, 7 boys) aged 14 years 5 months to 21 years 6 months, and 15 adults (9 females, 6 males) aged 23 years 9 months to 42 years 10 months. Twelve intellectually impaired children ( 7 girls, 5 boys), with chronological ages (CAs) between 3 years 7 months and 7 years 4 months, 
matched with the children with Down syndrome on social class and mental age( MA) [at the EDEI - Echelles Differentielles d'Efficience Intellectuelle (Perron-Borelli and Misès, 1974], served as controls on some of the tests. All the subjects with Down syndrome had standard trisomy 21 . The non-adults were attending primary or secondary special schools for the intellectually impaired. The adults were attending "La Fermette", an occupational day centre for adults with Down syndrome located in the vicinity of Verviers, in the Eastern part of Belgium. They all appeared to have normal or close to normal hearing and visual abilities (no specific examination was undertaken) and came mainly from middle-class families.

The language measures (administered in a randomized way) included: mean length of utterance (MLU) obtained from free-play or conversational speech, TVAP (Test de Vocabulaire Actif et Passif, Deltour and Hupkens, 1980; a receptive test of referential lexical knowledge), TVP (Test de Vocabulaire Productif, Comblain, 1993; an expressive test of referential vocabulary in which subjects are requested to label as many as 817 pictures representing common objects or actions, and corresponding to 20 basic semantic categories), as well as 8 receptive subtests from the difficulty level
1 of the BEMS (Batterie d'Evaluation Morpho-Syntaxique, Comblain, Fayasse, and Rondal, 1993). These subtests concern: the comprehension of personal pronouns, definite and indefinite articles, verbal inflexions, coordinate clauses, temporal locative, causal, and conditional subordinate clauses, relative clauses, negative and passive sentences. The subjects are requested either to select the picture most appropriately corresponding to the meaning of the proposed sentence in some subtests, or to act out the sentence with play material in some other subtests. The resulting data are summarized in Table 1. Only the data on adults with Down syndrome are of immediate interest.

Receptive lexical development in intellectually impaired persons is often reported to be consistent with mental age (MA). Comblain's data (items 3 and 4 on Table 1) reveal a mean receptive lexical age of about 5 years on the TVAP, which is about the MA level assumed to be reached by most adults with Down syndrome (cf. Gibson, 1978). On the expressive side, the adults with Down syndrome studied by Comblain could label correctly approximately $50 \%$ of the common objects and actions proposed. When it comes to lexical representation and organisation, however, the picture may be even less favourable. Indeed, there is no clear

Table 1. Group means and standard deviations (between parentheses) for the measures computed by Comblain (1994) on the language of Down syndrome (DS) children, adolescents, and adults, and non-intellectually impaired children matched with the children with Down syndrome on mental age and social class.

\begin{tabular}{|c|c|c|c|c|}
\hline \multirow[b]{2}{*}{ Categorical data } & \multicolumn{4}{|c|}{ Group (n) } \\
\hline & $\begin{array}{c}\text { Non- } \\
\text { intellectually } \\
\text { impaired } \\
\text { children (11) }\end{array}$ & $\begin{array}{c}\text { Children with } \\
\text { DS } \\
(11)\end{array}$ & $\begin{array}{c}\text { Adolescents } \\
\text { with DS } \\
(16)\end{array}$ & $\begin{array}{c}\text { Adults with DS } \\
\text { (15) }\end{array}$ \\
\hline $\begin{array}{l}\text { 1. Chronological age } \\
\text { (CA) }\end{array}$ & $3 ; 8$ & $9 ; 10$ & $18 ; 4$ & 30.8 \\
\hline 2. Mental age (MA) & & $3 ; 7$ & $5 ; 9$ & $4 ; 5$ \\
\hline $\begin{array}{l}\text { 3. Mean length of } \\
\text { utterance (MLU) - }\end{array}$ & & $2.08(1.04)$ & $4.75(2.50)$ & $4.73(2.98)$ \\
\hline 4. TVAP & & $3 ; 3(0 ; 5)$ & $5 ; 9(1 ; 11)$ & $4 ; 10(1 ; 5)$ \\
\hline 5. TVP & & $28.79(6.62)$ & $38.43(11.84)$ & $40.57(13.23)$ \\
\hline 6. Personal pronouns & $62.50(17.32)$ & $53.33(13.71)$ & $46.25(14.55)$ & $43.33(24.10)$ \\
\hline 7. Articles & $47.92(13.13)$ & $37.04(11.44)$ & $37.28(12.03)$ & $33.70(11.20)$ \\
\hline 8. Verbal inflexions & $44.94(13.50)$ & $41.67(8.14)$ & $44.55(10.12)$ & $40.28(7.81)$ \\
\hline 9. Coordinate clauses & $65.63(21.65)$ & $45.83(17.94)$ & $70.31(14.34)$ & $60.83(15.57)$ \\
\hline $\begin{array}{l}\text { 10. Subordinate } \\
\text { clauses }\end{array}$ & $75.00(19.66)$ & $48.33(16.42)$ & $51.25(26.05)$ & $34.29(22.43)$ \\
\hline 11. Relative clauses & $89.06(11.97)$ & $62.08(12.47)$ & $80.47(18.24)$ & $67.86(23.87)$ \\
\hline 12. Negative sentences & $89.06(11.06)$ & $34.38(21.40)$ & $64.84(21.99)$ & $41.96(34.88)$ \\
\hline 13. Passive sentences & $78.91(21.27)$ & $64.58(17.54)$ & $58.59(18.10)$ & $51.79(33.20)$ \\
\hline
\end{tabular}

Notes: CA, MA, and TVAP ages are expressed in years and months; MAs are global scores obtained at the EDEl; categories 5 to 13 are expressed in percent of correct answers; MLU is computed in number of words plus grammatical morphemes (according to Rondal, Bachelet, \& Peree's procedure, 1986); TVAP: Test de Vocabulaire Actif et Passif; TVP: Test de Vocabulaire Productif; Categories 6 to 13 are from the BEMS (Batterie d'Evaluation Morpho-Syntaxique); Dots indicate categorical data that were not collected. ANOVAs and follow-up analyses (Fisher LSDP) indicate that the following contrasts are significant at the $p<$ or $=.05$ level: non-intellectually impaired and children with DS on indices 7, 9, 10, 11; nonintellectually impaired children and adolescents with DS on indices $6,7,10,11,12,13$; non-intellectually impaired children and adults with DS on indices $6,7,10,11,12,13$; children with DS and adolescents on indices $3,4,9$, 11, 12; children with DS and adults on indices 3, 4, 5, 9; adolescents with DS and adults on indices 10, 13. 
Table 2. Group means and standard deviations (between parentheses) for the measures computed by Rondal and Lambert (1983) on the language of Down syndrome (DS) and intellectually impaired non-Down syndrome adults in free conversation with a non-intellectually impaired adult interlocutor.

\begin{tabular}{|l|c|c|}
\hline Indices & Adults with DS & $\begin{array}{c}\text { Non-DS intellectually } \\
\text { impaired adults }\end{array}$ \\
\hline 1. TTR & $.58(.08)$ & $.57(.05)$ \\
\hline 2. MLU & $5.98(2.62)$ & $6.95(2.52)$ \\
\hline 3. Proportion of sentences & $.41(.31)$ & $.53(.30)$ \\
\hline 4. Sentence complexity & $.22(.17)$ & $.33(.24)$ \\
\hline 5. Correct marking of number and gender & $.56(.24)$ & $.69(.21)$ \\
\hline 6. Proportion of correct articles & $.38(.21)$ & $.52(.15)$ \\
\hline 7. Proportion of correct pronouns & $.62(.50)$ & $.88(.50)$ \\
\hline 8. Proportion of correct verbal inflexions & $.55(.37)$ & $.78(.38)$ \\
\hline 9. Proportion of information & $.97(.05)$ & $.95(.07)$ \\
\hline 10. Proportion of new information & $.69(.12)$ & $.69(.11)$ \\
\hline 11. Conversational topic continuity & $.83(.08)$ & $.82(.12)$ \\
\hline
\end{tabular}

Note 1: TTR (type-token ratio): ratio of the number of different words (types) to the number of words in a speech sample (tokens); 2: MLU: mean length of utterance, computed in number of words plus grammatical morphemes according to Brown's rules (1973); 3: ratio of the number of sentences to the total number of utterances; 4: ratio of the number of compound verbs plus subordinate clauses to the total number of utterances; indices 5 to 8 are proportions computed on the total number of utterances; 9 : ratio of the number of items of information supplied verbally to the total number of utterances [by information, it was meant a relational meaning in the sense of Chafe's (1970) meaning analysis]; 10: ratio of the number of items of information not previously stated in the verbal exchange between interlocutors to the total numbers of items of information given in the speech sample; 11: proportion of times the intellectually impaired individual correctly followed in the exchange on the topic introduced by the interlocutor.

indication at this time that the mental lexicon of intellectually impaired (including Down syndrome) individuals is structured in functionally appropriate ways (see Barrett and Diniz, 1989, and Rondal, 1994b, for relevant data and theoretical suggestions concerning the hierarchical organisation, prototypicality, and the syntagmatic-paradigmatic dimension of the lexicon of intellectually impaired subjects).

Another lexical measure, type-token ratio (TTR), assessing lexical diversity of use, was computed by Rondal and Lambert (1983) on corpora of spontaneous (conversational) language from 22 French-speaking adults with Down syndrome. Table 2 supplies a summary of the quantitative observations in this study. Only Down syndrome TTR data are of immediate relevance.

As indicated in Table 2, observed TTRs are close to .58. This figure is difficult to interpret for lack of normative data in (adult) French-speaking or even English-speaking subjects. They can be compared to Rondal's TTR data obtained from free speech in American- English speaking children with Down syndrome in free play or conversation with their mothers (i.e. .44 for children younger than CA 6 years and .49 between CAS 6 and 12 years.

As tothematic semantics, adults with Down syndrome (see Rondal, 1978; Coggins, 1979; Layton and Sharifi, 1979; Duchan and Erickson, 1976) appear to structure their utterances - no matter how formally limited they may be - according to the same basic semantic relations as non-intellectually impaired people (i.e., agent, semantic object, instrumentation, beneficiary, location, attribution, etc.). They also seem to understand correctly the same set of basic structural meanings when these meanings are expressed in the speech of other people. There is no indication that the elementary semantic-structural basis of language is mark- edly different in non-intellectually impaired and Down syndrome persons at corresponding levels of language development.

To return to Table 1, mean MLU for the group of adults with Down syndrome studied by Comblain (1994) is 4.73 with a standard deviation of 2.98 . This is compatible with the corresponding figures reported by Fowler (1988) and Fowler, Gelman, and Gleitman (1994) for their late adolescent English-speaking Down syndrome subjects (MLU in the range of 3 to 3.50 ), but slightly lower than the figure reported by Rondal and Lambert (1983) with a group of young Frenchspeaking adults with Down syndrome (i.e. mean MLU 5.98, SD 2.62; cf. Table 2). MLU in intellectually impaired adults, as observed in free conversation, is usually in the vicinity of 12 words plus bound grammatical morphemes (according to the counting procedures proposed by Brown, 1973, and Rondal, Bachelet, and Peree, 1986). The important limitation in Down syndrome adults' MLUs reflects the formal simplicity of their utterances. It corresponds most characteristically to the limited use of clause co-ordination and subordination, the frequent lack or instability of grammatical morphemes (within the noun as well as the verb phrase), the frequent lack of phrase and clause connectors, and of course the overall reduced productivity of the language system. This is confirmed in the study by Rondal and Lambert (1983) already mentioned.

In this study, it was observed (see Table 2) that only about half of the utterances produced by adults with Down syndrome were grammatical clauses. Sentence complexity remained low. Grammatical marks of number and gender were produced on the average only once in two or two times in three utterances. Articles are used infrequently and verbs were not regularly inflected. Incidentally, in Rondal and Lambert's (1983) study (as illustrated also in Table 2), non- 
Down syndrome intellectually impaired (of mixed and/or unknown aetiologies) obtained scores generally higher on average than those of CA-matched Down syndrome adults. This is consistent with the suggestion sometimes made that the Down syndrome condition is more detrimental to language development than other pathological entities in moderate and severe intellectual impairment [see Fowler, (1990), and Kernan, (1990), for recent re-activations of this suggestion dating back at least to Zisk and Bialer,(1967)].

An interesting question is why the formal instability, particularly at the morphosyntactic level, in the expressive language of individuals with Down syndrome? Rondal (1985) (also see Rondal and Edwards, in preparation) suggested that at least a part of the explanation may reside in a too narrow processing capacity constraint in Down syndrome (and intellectually impaired) subjects limiting rather drastically the speaker's ability to allocate proper attentional and cognitive resources to the ongoing formal monitoring of language, hence the token-to-token inconsistency of grammatical productions. The more demanding the extralinguistic context, the nature of the speech act performed, and the content and formal aspects of the language to be produced, the more likely some of the less solidly established morphosyntactic features will tend to be eliminated from the productions or will cause errors.

At the textual (or discursive) level, little data are available. They suggest major expressive difficulties with regard to the paragraphic and discursive organisation. Text macrostructure is often poorly dealt with (for instance, in narrative activities, the usual sequential narrative structure is not regularly used, at times rendering comprehension problematic for the unfamiliar interlocutor). Text cohesion is often wanting by default or inappropriate use of standard cohesive devices (i.e., coreference, ellipsis - and presupposition -, conjunction, lexical cohesion; see Halliday, 1985).

Major problems exist also in sentence comprehension. As Table 1 indicates, on the BEMS, adults with Down syndrome give less than or equal to $50 \%$ correct responses in average value (with relatively important standard deviations for some linguistic categories, however) in the following categories: personal pronouns, articles, verbal inflexions, subordinate clauses, negative and passive sentences. Receptive performance is slightly better on relative clauses. These data confirm that the formal limitations observed in the expressive language of adults with Down syndrome also extend to the receptive side of the language.

Articulatory and phonological skills in adults with Down syndrome seem to correspond closely to those of children and adolescents with Down syndrome. The same speech characteristics, errors, problems, and reduced intelligibility are reported for adults with Down syndrome as for younger persons with Down syndrome. For instance, Shriberg and Widder (1990), and Hamilton (1993), for American English and English-speaking subjects with Down syndrome, respectively, and Van Borsel (1993), for Dutch-speaking adults with Down syndrome, all signal comparable consonant error rates and typical speech errors largely on the same types of phonemes (i.e., syllable final phonemes, consonant clusters, substitutions, additions, and omissions of particular phonemes). Hamilton's (1993) detailed technical analysis suggests the existence of several abnormal articulatory characteristics in adults with Down syndrome, such as more palatal zone contact for alveolar sounds $(/ \mathrm{t}, \mathrm{d}, \mathrm{n}, \mathrm{l} / \mathrm{)})$, longer closure duration for occlusive consonants, larger consonant transition times within clusters, difficulty with rapid tongue movements, etc. Hamilton (1993) confirms the existence of symptoms of dysarthria (i.e., breakdown in the ability to move the tongue and lips in order to articulate speech sounds accurately and rapidly), and dyspraxia (i.e., the ability to select, plan, and sequence the sounds needed in speech). In addition, Shriberg and Widder (1990) report abnormal suprasegmental characteristics, regarding five prosodic domains (i.e., rate of speech, stress, loudness, pitch, and quality of voice - relative harshness, hoarseness, or nasality) in the speech of their intellectually impaired and adult Down syndrome subjects.

Stuttering is also relatively frequent in adults with Down syndrome (perhaps even more frequently in males with Down syndrome) (see Preus, 1972). It may be that the incidence of stuttering increases slightly in individuals with Down syndrome from childhood to adulthood for reasons that are not known at the present time, but may have to do with increasing social and personal pressures in non-institutionalized Down syndrome adolescents and adults bearing on immature speech systems.

Lastly, regarding thepragmatic and linguistic communication levels of adults with Down syndrome. Limited information is currently available at this time on this topic. A good deal of the available information is summarized and discussed in Rosenberg and Abbeduto (1993). Some information on conversational topic continuity and topic contribution in Down syndrome adults' conversations were also gathered by Rondal and Lambert (1983) - see Table 2 here, lower portion. It is possible to summarize briefly this literature attesting to the nontrivial nature of Down syndrome persons' abilities in the pragmatical aspects of language and ordinary communication, as done in Table 3.

In summary, it seems possible to characterize the language of most adults with Down syndrome as formally restricted (particularly morphosyntactically), often deficient as to articulation and phonological processes, but semantically, pragmatically, and communicatively appropriate to minimal cognitive and social demands. Utterances are typically short (with MLUs around 5), monopropositional, with limited and inconsistent use of grammatical morphology. Purely linguistic comprehension is drastically limited rendering the reliance on lexical, informational, and situational cues all the more important. Despite such drastic shortcomings, the semantic structures and the contents of the utterances produced are correctly organized, the verbal production is informative, relevant, and generally appropriate to the social context and the communicative intents of the locutors. In particular, the major speech acts and conversational functions are accessible to the adults with Down syndrome even with reduced lexical and grammatical means.

No systematic comparison has been published to the best of our knowledge of the language of male and female adults with Down syndrome. It is not possible therefore to establish at the present time whether significant language differences exist between men and women with Down syndrome. In my view, such differences are unlikely except perhaps in the articulatory and intelligibility aspects of language (including stuttering and dysfluencies), possibly more frequent in males with Down syndrome, which may be the objective basis for 
Table 3. Levels of language pragmatic functioning in adults with Down syndrome.

\begin{tabular}{|c|c|}
\hline Pragmatic area & Level of functioning \\
\hline 1. Speech acts & $\begin{array}{l}\text { A. Individuals with Down syndrome are able to question, request, } \\
\text { answer, assert, suggest, command, acknowledge, commit } \\
\text { themselves, propose, and express feelings or opinions, like nor } \\
\text { intellectually impaired people, but with primitive linguistic mean } \\
\text { and not always use the indirect, softened, polite, or inferred } \\
\text { forms that normal people find appropriate. }\end{array}$ \\
\hline & $\begin{array}{l}\text { B. Receptively, individuals with Down syndrome eventually } \\
\text { become able to understand speech acts in familiar interactions } \\
\text { and settings but only associated with simple linguistic cognitive } \\
\text { and social demands. }\end{array}$ \\
\hline $\begin{array}{l}\text { 2. Repairing communication } \\
\text { failures }\end{array}$ & $\begin{array}{l}\text { Individuals with Down syndrome by adulthood seem to have the } \\
\text { skills necessary for responding to a variety of requests for repair } \\
\text { and to request repair of conversational failures. }\end{array}$ \\
\hline 3. Conversing and debating & $\begin{array}{l}\text { Individuals with Down syndrome exhibit appropriate turn-taking } \\
\text { behaviours in familiar conversational situations. They evidence } \\
\text { conversational topic continuity with peers as well as non- } \\
\text { intellectually impaired interlocutors, and they can meaningfully } \\
\text { contribute to the conversational topic. Information supplied and } \\
\text { organized discursively do not seem to be more redundant than } \\
\text { customary speech between familiar non-intellectually impaired } \\
\text { people. }\end{array}$ \\
\hline
\end{tabular}

the not uncommon opinion in educators and parents (e.g., Buckley and Sacks, 1987) that boys with Down syndrome are less well off with language than girls.

Actually, available studies involving systematic language comparisons of intellectually impaired boys and girls (including those with Down syndrome) (see Rondal and Edwards, in preparation, for a review and discussion) reveal little sex variation in a long list of speech and language features, except precisely on stuttering and dysfluencies often reported as being more frequent in intellectually impaired and Down syndrome males (e.g., Stansfield, 1990), which is also the statistical situation in non-intellectually impaired people (and may incriminate slightly greater fragility of some brain speech structures in men).

Also, as is known, Down syndrome is not an homogeneous entity at the cytogenetic and etiological level. Standard trisomy 21 (ST21) represents approximately $97 \%$ of the cases. In 1 or $2 \%$ of the cases, depending on the epidemiological studies, the genetic error takes place during the second or the third cell division (mosaicism). In the remaining 1 or $2 \%$ of the cases, the additional chromosome material is not a triplicate of chromosome 21 but a part or the totality of another chromosome (often chromosome 14 or 22). These are cases of translocation. We know that ST21, mosaicism, and translocation subtypes of Down syndrome display differences in dermatoglyphic, physical, clinical, and mental status (see Gibson and Pozsonyi, 1965; Baumeister and Williams, 1967; Fishler, 1975). Possible variation in language development and functioning could be expected depending on the aetiological subtype. Few specific data exist on this question unfortunately. They seem to suggest (e.g., Fishler and Koch, 1991) better lexical and semantic abilities in children and adolescents with mosaic Down syndrome, probably in proportion to their usually more advanced intellectual abilities (for reason of a neurological heterogeneity - genetically based and developmentally mediated - with the other subtypes of Down syndrome). No follow-up data are available concerning possible speech and language differences in adults with Down syndrome according to subtype of Down syndrome.

Lastly, it is important not to minimize the extent and generality of the inter-individual differences in the language functioning of persons with Down syndrome (exemplified in the relatively large SDs reported in the empirical studies; see Tables 1 and 2 above, for example). Such a variation must be taken into account theoretically and also practically, for example when planning social and work integration, leisure activities, and further education for those persons. At rare times, such individual differences may culminate in exceptional cases of language development and functioning in persons with Down syndrome (e.g., Seagoe, 1965, 1993; Rondal, 1994b) - there are corresponding exceptional cases language-wise in non-Down syndrome intellectually impaired subjects (e.g., Bellugi, Marks, Bihrle, and Sabo, 1988; Bellugi, Wang, and Jernigan, 1993; Curtiss, 1988; Cromer, 1991; Yamada, 1990). Most astonishingly, for example, Françoise the adult woman with Down syndrome studied by us, presents well-developed - to the point of being normal or normal like - computational language components, to use Chomsky's formula (i.e., phonology and morpho-syntax), expressively as well as receptively. Her 
language conceptual aspects (i.e., vocabulary and lexical abilities) and discursive abilities are more in correspondence with the limited cognitive abilities.

Cases such as Françoise and a few others (and it would seem that there are others "in store" awaited to be documented) constitute potent arguments in favour of the modular conception of language and the relative developmental autonomy of phonology and morpho-syntax, as suggested by authors such as Liberman and Mattingly (1989), Chomsky (1981, 1984), Moscovitch and Umilta (1990). In a more applied way, they strongly suggest that the extent of neurological heterogeneity in Down syndrome may be quite large, and even larger than expected. The specification of brain development in Down syndrome in a functionally oriented way is becoming a priority for advancing our comprehension of cognitive and language functioning (among other functions) in persons with Down syndrome. Also, systematic cognitive and language neurobiological comparisons of other intellectually impaired syndromes should be encouraged (such as the recently published study of Down syndrome and Williams syndrome subjects from neuropsychological, neurological, and neuroanatomical points of view by Bellugi, Bihrle, Jernigan, Trauner, and Doherty, 1990).

\section{Language progress in adults with Down syndrome} Is there spontaneous language progress in individuals with Down syndrome beyond adolescence and in adulthood? The answer to this question conditions the way we should plan further education for persons with Down syndrome beyond the early years. It is also reminiscent of the question of a critical period for language development as raised by Eric Lenneberg some years ago (1967), a question that is still with us with great acuity.

In the absence of longitudinal observations running from childhood into adulthood, the only way to answer (tentatively at the present time) the above question is to compare the language of adults with Down syndrome, backwards so to speak, to the language of adolescents and children with Down syndrome. In so doing, one is exposed to the criticism of applying a cross-sectional method to a longitudinal problem, and one is therefore liable to the usual reservations. But this is the only way open to us at present. In what follows, we will report the indications on the language of Down syndrome adults to that of Down syndrome adolescents and children in an attempt to provide a first answer to the life-span "progress or evolution question" as raised above (see also Rondal, 1988).

Summarizing a number of comparative research data originating in the work of Van Borsel (1988, 1991), Comblain (1994), Rondal et al. (1981), Rondal and Lambert (1983), in addition to the series of studies on pragmatical and linguistic communication in intellectually impaired (including Down syndrome) children, adolescents, and adults reviewed by Rosenberg and Abbeduto (1993), it seems that no progress can be ascertained in the receptive morphosyntactic aspects of the language of Down syndrome adults when compared to Down syndrome adolescents.

On the expressive side of morpho-syntax, the data are also consistent with the null hypothesis regarding developmental progress from adolescence to adulthood. No progress is obvious either in the phonological aspects of language in the adult years. In this respect, the empirical reports (e.g., Hamilton, 1993; Van Borsel, 1993) - in different languages - insist on the persistence of the same speech problems across the years. The conceptual and pragmatical aspects of language may offer a different developmental picture, however. No progress in receptive and expressive referential lexicon is attested in Comblain's (1994) data with adolescents and adults with Down syndrome (see Table 1 above), nor in diversity of lexical use [if one compares the spontaneous speech of intellectually impaired (including Down syndrome) adults and adolescents in the data of Rondal and Lambert, 1983, and Rondal et al., 1981].

However, Berry, Groenweg, Gibson, and Brown (1984) have reported a slight but significant increase in receptive lexical ability as attested by the scores on the Peabody Picture Vocabulary Test (PPVT) in a five-year longitudinal study of 31 young adults with standard trisomy 21 . Over this period of time, mean PPVT score changed from 56.9, (SD 18.4 ) to 61.3 , (SD 18.4), a moderate but statistically significant increase that paralleled (and perhaps was related to) a significant increase in nonverbal mental development as assessed by the Raven's Progressive Coloured Matrices as well as progress on an Index of Adaptive Functioning (devised at the University of Calgary, Canada). There may be, therefore, some modest but continued vocabulary growth in adults with Down syndrome. The pragmatic and communicative studies reviewed by Rosenberg and Abbeduto (1993) suggest continued development from childhood into adolescence and adulthood. But the lack of precise age-related comparisons in this corpus of studies makes it impossible to establish exactly where in time the specific developmental changes take place.

Basically the same conclusion can be reached regarding a possible language evolution from late childhood (say 12-14 years) and adolescence in Down syndrome (and other intellectually impaired) individuals, using the series of comparative data available (Bleile and Schwartz, 1984; Bray and Woolnough, 1988; Comblain, 1994; Dodd, 1976; Fowler, 1988; Fowler, Gelman, and Gleitman, 1994; Lenneberg, 1967; Rondal, 1978; Rondal et al., 1981; Rosenberg and Abbeduto, 1993; Ryan, 1975; Smith and Stoel-Gammon, 1983; Stoel-Gammon, 1980; Van Borsel, 1988).

In other words, there is no clear empirical indication at this time that substantial development takes place beyond 1214 years in the computational language aspects of Down syndrome (and other intellectually impaired) individuals whereas there may be some continued progress with age in lexical referential and pragmatical/communicative abilities, expressively as well as receptively.

Most interestingly, it is ascertained in the studies of language-wise exceptional Down syndrome and intellectually impaired subjects (references given above) that these subjects developed their excellent morphosyntactic and phonological abilities between approximately 4 and 10 years CA. This attests two things: first, the existence of a delay in phonological and grammatical development in these subjects approximately of the same magnitude as those usually observed in typical intellectually impaired (and Down syndrome) subjects. This delay represents the additional amount of time needed for moderately and severely intellectually impaired individuals to develop the cognitive- semantic basis from which lexical and grammatical development may 
then proceed. Second, once they have started developing, linguistically exceptional intellectually impaired subjects proceed relatively quickly in their grammatical development (over a 4 or 5 year-period as it would seem) but, and this is the crucial point, within childhood. All in all, the above data are fairly compatible with the hypothesis of the existence of a critical period for computational language development in intellectually impaired as well as in non-intellectually impaired children, as suggested by Lenneberg (1967). As is known, this hypothesis has found a convincing empirical basis in the work of Curtiss and associates with Genie, a modern-day "wild child" kept away from social contact for most of the 13 years of her life (Curtiss, 1977), and in the repeated demonstration (e.g., Mayberry, Fisher, and Hatfield, 1983, Ploog, 1984; Newport, 1984, 1990, 1992) that "late" learners of the American Sign Language (ASL, the esoteric sign system used by deaf people in the United States of America) - i.e., deaf individuals first exposed to ASL after age 12 - never learn to sign and never develop grammatical knowledge in ASL as native ASL signers or subjects first exposed to ASL in their earlier years, even after 30 years of practice.

According to Hurford (1991), the major determinant for the end point of the critical period (around 12 years) is the evolutive consequence of the interplay of genetic factors influencing life-history characteristics in relation to language acquisition. If the ending of the critical period for computational language development is controlled by genetic factors and is the product of evolution, as Hurford suggests, there is no reason why intellectually impaired persons (including those with Down syndrome) should escape it. Regarding phonological and morpho-syntactic development, it may well be the case that moderately and severely intellectually impaired individuals are squeezed, so to speak, between two constraining time parameters: (1) late onset of development (for brain-maturational reasons and because of the longer time necessary to set a sufficient cognitive-semantic basis from which computational language can proceed); (2) the ending of the critical period for basic structural development.

Conceptual and social-communicative aspects of language do not appear to be constrained in similar ways by biological-time factors. Development may continue in these aspects for years beyond puberty, at least in some ways; and this seems to be true for intellectually impaired persons as well. This is compatible with the possibility of a slow continued growth in MA in Down syndrome people in the third and fourth decades of life (cf. Berry et al., 1984).

Spelling out the practical implications of the above considerations, one will insist that every educative effort should be made to help children with Down syndrome to develop their phonological and morpho-syntactic skills before 12 years or so, for the benefits of later training become less and less with time beyond this stage. Regarding vocabulary and the pragmatic and social aspects of language, more developmental time may be available to the trainers. Of course, this would not be a good idea not to use maximally the early years for training purposes but further training beyond 12 years can have some efficacy, and it should probably go on until the mid-adult years.

\section{Ageing, Alzheimer disease, and the language of individuals with Down syndrome}

Normal ageing (i.e., beyond, say, 65 years) - not talking of senility or pathological ageing such as the effects of Alzheimer disease, Pick disease or other degenerative diseases - is known to induce physiological and neuropsychological changes that can affect language and communication. For example, psychomotor performance is slower in older persons. Respiratory supportfor speech is less efficient. Changes in laryngeal functioning contribute to modification of voice pitch (Honjo and Isshiki, 1980). Hearing problems affect a large proportion of older people (so-called presbyacousis; Willot, 1991). Perception of fast rates of speech, speech in noise, whispered and higher pitched voices is reduced; resulting, for instance, in difficulties in communicating on the telephone. Loss of vision determining loss of visual information can also affect communication.

Cognitive deterioration may take place in selective attention (particularly divided attention situations). The process of learning and retaining new information becomes more limited with advancing age. Different types of memory are affected by the ageing process. There may be a mild decrease in short-term memory (STM) in older subjects although this varies according to factors such as the complexity of the information to be recalled (Craik and Rabinowitz, 1985). A number of studies bearing on the functioning of working memory (the version of STM in Baddeley's theory; Baddeley, 1990) in older persons suggest that the mechanism identified by Baddeley under the name of "central executive" could be particularly affected by the ageing process, hence provide fewer attentional and (secondary) storing resources. The auditory-verbal and the visuo-spatial stores could also be reduced as well as their processing speed (Salthouse and Babcock, 1991).

The decline in long-term memory (LTM) capacity in older persons may be more significant. Differences between younger and older individuals relate to encoding, organizational, and retrieval factors and strategies (Rankin and Collins, 1985). Some LTM subsystems resist ageing better than others. For example, episodic memory (i.e., autobiographical memory; Tulving, 1983) is more age-sensitive than memories for perceptual representation or semantic memory (i.e., the memory for language and knowledge).

What about language change in the elderly population? Specific information is still relatively sparse. Grammatically, there is some evidence that the ability of the elderly to understand complex and/or long sentences may be reduced. The same situation prevails for grammatical sentences that are ambiguous and demand processing flexibility (e.g., potentially ambiguous double-object sentences such as "He showed her baby pictures") (Scholes, 1978), and for sentences containing a temporal subordinate clause headed by "before" or "after". This is particularly true when the order of mention in the sentence differs from the order of occurrence of the referred events (e.g., "He went out after having breakfast", as opposed to "He had breakfast before going out") (Maxim, 1982).

Older people have more difficulty than younger people in extracting information from spoken texts (Cohen, 1979). This is obvious when inferential questions are asked about the text (as opposed to direct questions). It could be that the elderly have particular difficulty with text inferences when 
problem solving and complex linguistic analyses have to be carried out at the same time.

Fewer descriptions of the language that older adults produce are available. Proportions of dysfluencies are higher than in the speech of younger people (Yairi and Clifton, 1972). However, these dysfluencies seem to be for the major part hesitant interjections and fillers, probably attesting the longer time the elderly need to process utterances for production. Consistent with the indication of a possible organizational difficulty in oral language output, is Davis (1979) observation that older adults use fewer embedded clauses (known to be more demanding of processing resources) than middle-age groups; an observation not made in written language where more time is available to monitor complex expression (Obler, Mildworf, and Albert, 1977).

No particular segmental phonological difficulties are reported in normal ageing. Older people show changes in single-word processing. They usually are slower on fluency tasks such as producing names within one semantic category in a period of time. Given additional time, however, the elderly achieve the same results as younger controls.

The problem that the elderly themselves mention most frequently is increased difficulty in word retrieval hence the augmented use of semantically indefinite words and third-person pronouns in discourse with increasing age. A decline in the ability to retrieve from lexicon is likely in older age. Prevalent among lexical difficulties are those related to proper nouns (e.g., Lovelace and Twohig, 1991). The reasons are not well understood. They may have to do with the fact that proper nouns refer to individual entities and not to categories of entities as common nouns do. This drastically reduces the ways available to activate lexical entries for proper nouns (priming effect).

\section{What about normal ageing in intellectually impaired indi- viduals? \\ There is no reason not to expect intellectually impaired (including Down syndrome) persons to present the same ageing characteristics, psychological and otherwise, and to the same degree and extent, as non-intellectually impaired people. The limited information available to date on cogni- tive ageing in individuals with Down syndrome confirms this indication.}

Changes in sensory systems have been acknowledged as common consequences of ageing in the intellectually impaired population. Some deficits may be particularly common among ageing people with Down syndrome when compared to non-Down syndrome intellectually impaired people. Evenhuis, Van Zanten, Borcaar and Roerdinkholder (1992) have described hearing losses of $20 \mathrm{db}$ to over $90 \mathrm{db}$ at the speech frequencies (circa $3000 \mathrm{~Hz}$ ) in 33 out of 35 Dutch adults with Down syndrome aged 35-62 years. Cochlea losses were noted in $69 \%$ of the cases. Evenhuis et al. suggest that hearing loss should be considered as a contributing factor in the social and mental decline of middle-age persons with Down syndrome. Ocular findings from 30 individuals with Down syndrome aged 21-72 years are reported by Hestnes, Sand, and Tostad (1991). Strabismus, cataract, and visual losses were found to affect almost all subjects to various degrees.
Language studies of normally ageing individuals with Down syndrome are almost non-existent. In the only systematic study that I was able to locate, Young and Kramer (1991) investigated age differences in 60 adults with Down syndrome (aged 22-67 years), reportedly with no hearing impairment. Older subjects were less likely to attend to auditory stimuli, had poorer word discrimination, and were less able to understand the meaning of spoken language. Expectedly, these older subjects had more difficulty in following verbal directions.

It is possible to be more specific, at least predictively, in extrapolating from the language literature on normal ageing. Table 4 summarises these predictions, of course pending empirical verification.

Table 4. Additional language problems in ageing persons with Down syndrome.

1. Slower productive and receptive language processing

2. Less efficient respiratory support for speech.

3. Aggravated hearing problems; hence reduced attention to auditory stimuli, particular difficulties in perceiving whispered speech, speech in noisy conditions, and in communicating on the telephone.

4. Additional difficulties in linguistic analysis and information extraction from spoken discourse. Additional problems in following verbal directions.

5. Augmented rates of dysfluencies (particularly hesitation pauses, interjections, and fillers).

6. Additional difficulties in organizing spoken discourse.

\section{Reduced word fluency.}

8. Increased difficulty in word discrimination, and in retrieving common and proper nouns.

Language therapy intervention with the non-intellectually impaired elderly (e.g., Maxim and Bryan, 1994) could be adapted to the ageing person with Down syndrome. It could help reduce their processing difficulties, if only partially. Also the social environment of ageing intellectually impaired persons can be adapted relatively easily to the language limitations in these people (e.g., speaking more slowly and loudly to the older person with Down syndrome, using shorter and formally simpler utterances, allowing them additional time to process incoming language and to respond verbally).

Unfortunately, for a number of older persons with Down syndrome, there is more to ageing than physiological ageing. They may develop a debilitating degenerative disease known as Alzheimer disease (AZ), also occurring in older non-intellectually impaired and non-Down syndrome intellectually impaired people but with a lower incidence. In Alzheimer disease, the brain neurons develop neurofibrillary tangles i.e. flame-shape alterations composed mainly of condensed cytoskeletal proteins. Another protein, 8/ 
A4amyloid is deposited in large amounts in the form ofsenile or neuritic plaques, and around blood vessels causing reduced blood flow (amyloid angiopathy). The gradual accumulation of these changes plus neuronal loss, alteration of motor nuclei of brain stem, and reduction of neurotransmitters, render the affected parts of the brain less and less able to function properly, hence the functional Alzheimer disease symptomatology.

The particular cytogenetic association between Down syndrome and Alzheimer disease is beginning to be better understood. There are several suspected genetic causes of Alzheimer disease in non-Down syndrome people, possibly involving several chromosomes, which we will not consider here (see, for example, several contributions to the edited book by Berg, Karlinsky, and Holland, 1993). In the case of trisomy 21 , one possible partial explanation (there are alternative ones currently under scrutiny) is that the amyloid precursor protein (APP) gene resides on chromosome 21 (in the proximal part of the long arm of chromosome 21) (Goldgaber, Lerman, McBride, Saffiotti, and Gajdusek, 1987; Hyman, 1992). Indeed Alzheimer disease-like pathology has been demonstrated with animals transgenic for a fragment of the APP (Kawabata, Higgins, and Gordon, 1991). Neurofibrillary tangle-like structures were also reported in animals whose brains had been injected with 8/A4 amyloid protein itself (Kowall, Beal, Busciglio, Duffy, and Yankner, 1991). In trisomy 21, it is possible that overproduction of the APP leads to alterations in brain morphology. Neuropathological examination of individuals with Down syndrome who have died before the fifth decade show a few neurofibrillary tangles and neuritic plaques in some areas and layers of the brain (not to be considered here). The continued accumulation of these changes results in brain dysfunction and consequently cognitive decline by the 50 s or the 60 s (Hyman, 1992). The brain changes involved are the same biochemically as those characterizing Alzheimer disease in older non-intellectually impaired persons.

It is estimated that in non-intellectually impaired persons, approximately $3 \%$ will develop Alzheimer disease before or around 60 years. The incidence increases to about $20 \%$ beyond 75 years (e.g., Evans et al., 1989 - it should be noted, however, that this figure may encompass degenerative diseases other than Alzheimer disease). These figures may probably be transposed (and perhaps augmented) 15 or 20 years earlier in life for persons with Down syndrome. Most importantly, in Down syndrome, there seems to be a 15-year delay between the first major alterations at brain level and the behavioural manifestations of cognitive decline. In nonintellectually impaired people, the corresponding delay is only approximately 7 years. The reason for this difference is not known. This period, particularly in Down syndrome, offers time space for psychopharmacological and behavioural interventions with the prospect of slowing down the progress of the disease. It is possible that cognitive decline accelerates only from the time when alterations become so extensive as to overwhelm the functional compensatory mechanisms of the brain.

At the present time, there is virtually no systematic study of cognitive and linguistic decline in individuals with Down syndrome with clearly diagnosed Alzheimer disease. Suggestions can be made on what to expect from the beginning literature on the particular language problems of non-intellectually impaired persons with Alzheimer disease.
It would seem that language is compromised at all stages in Alzheimer disease but that there is enormous variation in deficits among individuals. Despite such a large variation, general lines of major symptomatology may be traced. Language changes in Alzheimer disease are most apparent at the semantic level (particularly, reduction of available vocabulary and breakdown of semantical associations) (Martin, 1987). Difficulty in word finding is one of the most noticeable feature of Alzheimer disease. Auditory comprehension of words also shows deficits, as well as the comprehension of semantic complexity in sentences and paragraphs (Hart, 1988). The quality of discourse, cohesion, and, in short, the whole pragmatics of language are usually found to be gravely deteriorating (see Maxim and Bryan, 1994, for a review).

Most interesting is the repeated observation that the computational aspects of language (and particularly the grammatical structures) are largely spared in Alzheimer disease. They may be disturbed because of the breakdown in the language conceptual aspects, but no or only little as the primary effect of Alzheimer disease pathology (Appel, Kertesz, and Fishman, 1982). For example, Kempler, Curtiss, and Jackson (1987) observed a normal range and frequency of syntactic constructions (but poor lexical use) in the spontaneous speech as well as in writing with a group of 20 non-intellectually impaired patients with Alzheimer disease. These data are suggestive of a dissociation between semantic and syntactic levels in Alzheimer disease reflecting the modularity characteristics of the functional organisation of language and the fact that organic deterioration in Alzheimer disease has a predilection for certain brain sites (at least at the earlier stages) leaving others untouched (e.g.. those underlying syntactic processing).

Table 5 briefly summarizes the probable implications of the above observations from non-intellectually impaired Alzheimer disease patients to Alzheimer disease in individuals with Down syndrome.

Table 5. Predicted language profile associated with Alzheimer disease in persons with Down syndrome.

Major dissociation between language computational (phonology and morpho-syntax) and language conceptual and social aspects (lexicon, semantics, pragmatics, discourse organisation and comprehension): the former aspects (underdeveloped in persons with Down syndrome) being little touched directly (they may be affected indirectly as a result of the cognitivesemantic breakdown), whereas the latter aspects will be found deteriorating to an extent varying from person to person.

Concluding, we are searching and gradually building a lifespan psycholinguistics and neurolinguistics of Down syndrome (Rondal, 1988) that will put us in a better position to advance educational intervention and management of persons with Down syndrome and make their effects more durable and generalisable. 


\section{References}

Appell, J., Kertesz, A., and Fishman, M. (1982). A study of language functioning in Alzheimer's patients. Brain and Language, 17, 73-91.

Baddeley, A. (1990). Human memory. Theory and practice. London: Erlbaum.

Baird, P., and Sadovnick, A. (1988). Life expectancy in Down syndrome adults, Lancet, 1354-1356.

Barrett, M., and Diniz, F. (1989). Lexical development in mentally handicapped children. In M. Beveridge, G. ContiRamsden, and Y. Leudar (Eds.), Language and communication in mentally handicapped people. London: Chapman and Hall.

Baumeister and Williams (1967). Relationships of physical stigmata to intellectual functioning in mongolism. American Journal of Mental Deficiency, 71, 586-592.

Bellugi, U., Wang, P., and Jernigan, J. (1993). Williams syndrome: An unusual neuropsychological profile. In S. Borman and J. Grafman (Eds.), Atypical cognitive deficits in developmental disorders: Implication for brain function (pp. 23-56). Hillsdale, NJ: Erlbaum.

Bellugi, U., Marks, S., Bihrle, A., and Sabo, H. (1988). Dissociation between language and cognitive functions in Williams syndrome. In D. Bishop and K. Mogford (Eds.), Language development in exceptional circumstances (pp. 77-189). London: Churchill Livingstone.

Bellugi, U., Bihrle, A., Jernigan, T., Trauner, D., and Doherty, S. (1990). Neuropsychological, neurological and neuroanatomical profile of Williams syndrome. American Journal of Medical Genetics Supplement, 6, 115-125.

Berg, J., Karlinsky, H., and Holland, A. (Eds.) (1993). Alzheimer disease, Down syndrome, and their relationship. New York: Oxford University Press.

Berry, P. Groenweg, G., Gibson, D. and Brown, R. (1984). Mental development of adults with Down syndrome. American Journal of Mental Deficiency, 89, 252-256.

Bleile, K., and Schwarz, I. (1984). Three perspectives on the speech of children with Down's syndrome. Journal of Communication Disorders, 17, 87-94.

Bray, M., and Woolnough, L. (1988). The language of children with Down's syndrome aged 12 to 16 years. Child Language Teaching and Therapy, 4, 311-321.

Brown, R. (1973). A first language. Cambridge, MA: Harvard University Press.

Buckley, S., and Sacks, B. (1987). The adolescent with Down's syndrome - life for the teenager and for the family. Portsmouth, UK: Portsmouth Down's Syndrome Trust.

Carter, C. (1958). A life-table for mongols with the causes of death. Journal of Mental Deficiency Research, 2, 64-74. Chafe, W. (1970). Meaning and the structure of language. Chicago: The University of Chicago Press.

Chomsky, N. (1981). Lectures on government and binding. Dordrecht: Foris.

Chomsky, N. (1984). Modular approaches to the study of mind. San Diego, CA: San Diego State University Press.

Coggins, T. (1979). Relational meaning encoded in twowords utterance of stage1 Down's syndrome children. Journal of Speech and Hearing Research, 22, 166-178.

Cohen, G. (1979). Language comprehension in old age. Cognitive Psychology, 11, 412-429.

Comblain, A. (1994). Memoire de travail et langage dans le syndrome de Down. Doctoral dissertation in progress. Universite de Liege, Laboratoire de Psycholinguistique. Comblain, A. (1993). Test de Vocabulaire Productif. (unpublished experimental version). Universite de Liege, Laboratoire de Psycholinguistique.
Comblain, A., Fayasse, M., and Rondal, J.A. (1993).Batterie d'Evaluation Morpho-Syntaxique (BEMS) (unpublished experimental version). Universite de Liege, Laboratoire de Psycholinguistique.

Craik, F., and Rabinowitz, J. (1985). The effects of presentation rate and encoding task on age-related memory deficits. Journal of Gerontology, 40, 309-315.

Cromer, R. (1991). Language and thought in normal and handicapped children. London: Blackwell.

Curtiss, S. (1977). Genie: A psycholinguistic study of a modern-day "wild child". New York: Academic Press. 22 Curtiss, S. (1988). The special talent of grammar acquisition. In L. Obler and D Fein (Eds.), The exceptional brain (pp. 364-386). New York: Guilford Press.

Davis, S, (1979). An investigation inro the language of the elderly (unpublished master's thesis). University of London, College of Speech Therapists.

Deltour, J.J., and Hupkens, D. (1980). Test de Vocabulaire Actif et Passif. Issy-les- Moulineaux, France: Editions Scientifiques et Psychologiques.

Dodd, B. (1976). A comparison of the phonological systems of mental age matched normal, severely subnormal and Down's syndrome children. British Journal of Communicative Disorders, 11, 27-42.

Dolk, H., De wals, P., Gillerot, Y., Lechat, M., Ayme, S., Beckers, R., Bianchi, F., Borlee, I., Calabor, A., Calzolari, E., Cuschieri, A., Galanti, C., Goujard, J., Hansen-Koening, D., Harris, F., Kargut, G., Lillis, D., Luugarotti, M., Lye, F., Marchi, M., Nervin, N., Radie, A., Stool, C., Stone, D., Svel, I., Teu Kate, L., and Zori, R. (1990). The prevalence at birth of Down syndrome in 19 regions in Europe 1980-86. In W. Fraser (Ed.) Key issues in mental retardation research (pp. 3-11). London: Routledge.

Duchan, J.F., and Erickson, J.G. (1976). Normal and nonretarded children's understanding of semantic relations in different verbals contexts. Journal of Speech and Hearing Research, 1 9, 767-776.

Evans, D., Funkenstein, H., Albert, M., Schezz, P., Cook, N., Chown, M., Hebert, L., Hennekens, C., and Taylor, J. (1989). Prevalence of Alzheimer's disease in a community population of older persons. Journal of the American Medical Association, 262, 2551- 2556.

Evenhuis, H., Van Zanten, G., Brocaar, M., and Roerdinkholder. W. (1992). Hearing loss in middle-age in persons with Down syndrome. American Journal on Mental Retardation, 9 7, 47-56.

Fishler, K. (1975). Mental development in Mosaic Down's syndrome as compared with trisomy 21 . In R. Koch and F. de la Cruz (Eds.), Down's syndrome (pp. 157-179). New York: Brunner/Mazel.

Fishler, K., and Koch, R. (1991). Mental development in Down syndrome mosaicism. American Journal on Mental Retardation, 96, 345-351.

Fowler, A. (1988). Determinants of rate of language growth in children with Down Syndrome. In L. Nadel (Ed.), The psychobiology of Down Syndrome (pp. 217-245), Cambridge, MA: MIT Press.

Fowler, A. (1990). Language abilities in children with Down syndrome: Evidence for a specific syntactic delay. In D. Cicchetti and Beeghly (Eds.), Children with Down syndrome: A developmental perspective (pp. 302-328). New York: Cambridge University Press.

Fowler, A., Gelman, R., and Gleitman, L.(1994). The course of language learning in children with Down syndrome. In $\mathrm{H}$. Tager-Flusberg (Ed.), Constraints on language acquisition: Studies of atypical children (pp. 91-140). Hillsdale, NJ: 
Erlbaum.

Gibson, D. (1978). Down's syndrome. The psychology of mongolism. New York: Cambridge University Press.

Gibson, D., and Pozsonyi, J. (1965). Morphological and behavioral consequences of chromosome subtype in mongolism. American Journal of Mental Deficiency, 69, 801804.

Golgaber, D., Leman, M., McBride, O., Saffiotti, U., and Gajdusek, D. (1987). Characterization and chromosomal localization of a cDNA encoding brain amyloid of Alzheimer's disease. Science, 235, 877-880.

Hamilton, C. (1993). Investigation of the articulatory patterns of young adults with Down's syndrome using electropalatography.Down's Syndrome: Research and Practice, $1,15-28$

Hart (1988). Language and dementia: a review. Psychological Medicine, 18, 99-112.

Hestns, A., Sand, T., and Tostad, K. (1991). Ocular findings in Down's syndrome. Journal of Mental Deficiency Research, 35, 194-203.

Honjo, I., and Isshiki, N. (1980). Laryngoscopic and voice characteristics of aged persons.Archives of Otolaryngology, 106, 149-152.

Hurford, J. (1991). The evolution of the critical period for language acquisition. Cognition, 40, 1 59-201.

Hyman, B. (1992). Down syndrome and Alzheimer Disease. In L. Nadel and C. Epstein (Eds.), Down syndrome and Alzheimer disease. Progress in Biological Research (Vol 379, pp. 123-142).). New York: Wiley-Liss.

Kawabata, S., Higgins, G., and Gordon, J. (1991). Amyloid plaques, neurofibrillary tangles and neuronal loss in brain of transgenic mice overexpressing a C-terminal fragment of human amyloid precursor protein. Nature, 354, 476-478.

Kempler, D., Curtiss, S. and Jackson, C. (1987). Syntactic preservation in Alzheimer's disease. Journal of Speech and Hearing Research, 30, 343-350.

Kernan, K. (1990). Comprehension of syntactically indicated sequence by Down's syndrome and other mentally retarded adults. Journal of Mental Deficiency Research, 34 169-178.

Kowall, N., Beal, M., Busciglio, J., Duffy, L., and Yankner, B. (1991). An in vivo model for the neurodegenerative effects of $d$ amyloid and protection by substance P.Proceedings of the National Academy of Science of the United States of America, 88, 7247-7251.

Layton, T., and Sharifi, H. (1979). Meaning and structure of Down's syndrome and non- retarded children spontaneous speech. American Journal of Mental Deficiency, 83, 139445.

Lenneberg, E. (1967). Biological foundation of language. New York: Wiley.

Liberman, A. and Mattingly, I. (1989). A specialization for speech perception revised. Cognition, 21, 1-36.

Lovelace, E., and Twohig, P. (1990). Healthy older adults' perceptions of their memory functioning and use of mnemonics. Bulletin of the Psychonomic Society, 29, 33-35.

Mann, D., and Esiri, M. (1988). The site of the earliest lesions of Alzheimer's disease. New England Journal of Medecine, 318, 789-790.

Martin, A. (1987).Representations of semantic and spatial knowledge in Alzheimer's patients: implications for models of preserved learning and amnesia. Journal of Clinical and Experimental Nevropsychology, 9, 121-124.

Maxim, J. (1982). Language change with increasing age, In M. Edwards (Ed.), Communication changes in elderly peo- ple (pp, 126-148). London: College of Speech Therapists, Monograph $\mathrm{N} 3$.

Maxim, J., and Bryan, K. (1994). Language of the elderly; A clinical perspective. London: Whurr.

Mayberry, R., Fisher, S. and Hatfield, N. (1983). Sentence repetition in American Sign Language. In J. Kyle and B. Woll (Eds.), Language in sign: International perspective on sign language (pp. 206-214). London: Croom Helm.

Moscovitch, M., and Umilta, C. (1990). Modularity and neuropsychology: Modules and central processes in attention and memory. In M. Schwartz (Ed.), Modular deficits in Alzheimer-type dementia (pp. 1-59). Cambridge, MA: MIT Press.

Newport, E. (1984). Constraints on learning. Studies in the acquisition of language. Papers and Reports on Child Language Development (Stanford University), 23, 1-22.

Newport, E. (1990). Maturational constraints on language learning. Cognitive Science, 14, 11-28.

Newport, E. (1992). Contrasting conception of the critical period for language. In S. Carey and R. Gelman (Eds.), The epigenesis of mind: Essays on biology and cognition (pp. 111- 130). Hillsdale, NJ: Erlbaum.

Obler, L., Mildworf, B., and Albert, M. (1977). Writing style in the elderly. Montreal: Academy of Aphasia Abstracts.

Oliver, C., and Holland, A. (1986). Down's syndrome and Alzheimer's disease: A review. Psychological Medecine, 16, 307-322.

Perron-Borelli, M., and Mises, R. (1974). Echelles Differentielles d'Efficience Intellectuelle. Issy-lesMoulineaux: Editions Scientifiques et Psychologiques.

Ploog, D. (1984). Comment on J. Leiber's paper. In R. Harre and V. Reynolds (Eds.), The meaning of primate signals ( $\mathrm{p}$. 88). Cambridge, UK: Cambridge University Press.

Preus, A. (1972). Stuttering in Down's syndrome. Scandinavian Journal of Educational Research, 16, 89-104. Preus, A. (1984). The Williams syndrome: Objective definition and diagnosis. Journal of Clinical Genetics, 25, 422428.

Rankin, J. and Collins, M. (1985). Adult age differences in memory elaboration. Journal of Gerontology, 40, 451-458. Rondal, J. A. (1975). Developpement du langage et retard mental: Une revue critique de la litterature en langue anglaise. L'Annee Psychologique, 75, 513-547.

Rondal, J. A. (1978a). Developmental sentence scoring procedure and the delay-difference question in language development of Down's syndrome children.Mental Retardation, 16, 169-171.

Rondal, J. A. (1978b). Maternal speech to normal and Down's syndrome children matched for mean length of utterance. In E. Meyers (Ed.), Quality of life in severely and profoundly mentally retarded people: Research foundations for improvement (Monograph Series No. 3., pp. 193-265). Washington, D.C.: American Association on Mental Deficiency.

Rondal, J. A. (1978c). Patterns of correlations for various language measures in mother- child interactions for normal and Down's syndrome children.Language and Speech, 21, 242-252.

Rondal, J. A. (1978d). Langage et education. Brussels: Mardaga.

Rondal, J. A. (1980a). Une note sur la theorie cognitivemotivationnelle d'Edward Zigler en matiere de retard mental culturel-familial. Psychologica Belgica, 20, 61-82.

Rondal, J. A. (1980b). Language delay and language difference in moderately and severely mentally retarded children. Special Education in Canada, 54, 27-32. 
Rondal, J. A. (1984). Linguistic and prelinguistic development in moderate and severe mental retardation. In $\mathrm{J}$. Dobbing, A. Clarke, J. Corbett, J. Hogg, and R. Robinson (Eds.), Scientific studies in mental retardation (pp. 323-345). London: The Royal Society of Medicine and MacMillan.

Rondal, J. A. (1985a). Langage et communication chez les handicapes mentaux. Brussels: Mardaga.

Rondal, J. A. (1985b). Adult-child interaction and the process of language acquisition. New York: Praeger.

Rondal, J. A. (1988a, 1993). Down's syndrome. In D. Bishop and K. Mogford (Eds.), Language development in exceptional circumstances (pp. 165-176). London: Churchill Livingstone. (republished by Erlbaum, Hillsdale, NS).

Rondal, J. A. (1988b). Language development in Down's syndrome: A life-span perspective. International Journal of Behavioural Development, 11, 21-36.

Rondal, J. A. (1994a). Exceptional cases of language development in mental retardation: The relative autonomy of language as a cognitive system. In H. Tager-Flusberg (Ed.), Constraints on language acquisition: Studies of atypical children (pp. 155-174). Hillsdale, NJ: L. Erlbaum.

Rondal, J. A. (1994b). Exceptional language development in Down syndrome. Implications for the cognition-language relationship. New York: Cambridge University Press.

Rondal, J. A. (1994c, in press). Especificidad sistemica del lenguaje en el sindrome de Down. In J. Perera (Ed.), Especificidad en el sindrome de Down. Madrid: Salvat.

Rondal, J.A. (1994d). Exceptional language development in mental retardation: Natural experiments in language modularity. Current Psychology of Cognition (Cahiers de Psychologie Cognitive) 13, 427-467.

Rondal, J. A., Coquiart, P., Crommen, T., Marissiaux, P., Neuville, P., Rolin, K., and Thonon, C. (1981). Aspects $d u$ langage de sujets handicapes mentaux adolescents. Liege: University of Liege, Experimental Psychoiogy and Psycholinguistics (unpublished).

Rondal, J.A., and Edwards, S. (in preparation). Language in mental retardation. Theory, problems, and remediation. London: Whurr.

Rondal, J. A., and Lambert, J. L. (1983). The speech of mentally retarded adults in a dyadic communication situation: Some formal and informative aspects. Psychologica Belgica, 23, 49-56.

Rondal, J.A., Bachelet, J.F., and Peree, F. (1986). Analyse du langage et des interactions verbales adulte-enfant. Bulletin d'audiophonologie, 5-6, 507-535.

Rosenberg, S., and Abbeduto, L. (1993). Language and communication in mental retardation. Development, processes, and intervention. Hillsdale, NJ: Erlbaum.

Ryan, J. (1975). Mental subnormality and language development. In E. Lenneberg (Ed.), Foundations of language development: A multidisciplinary approach (Vol. 2, pp. 269 277). New York: Academic Press.

Salthouse, T., and Babcock, R. (1991). Decomposing adult age differences in working memory. Developmental Psychology, 26, 763-776.

Scholes, R. (1978). Syntactic and lexical components of sentence comprehension. In A. Caramazza and E. Zurif (Eds.), Language acquisition and language breakdown (pp. 78-94). Baltimore: John Hopkins University Press.

Seagoe. M. (1965). Verbal development in a mongoloid. Exceptional children, 6, 229-275.

Shriberg, L., and Widder, C. (1990). Speech and prosody characteristics of adults with mental retardation. Journal of Speech and Hearing Research, 33, 627-653.

Smith, B., and Stoel-Gammon, C. (1983). A longitudinal study of the development of stop consonant production in normal and Down's syndrome children. Journal of Speech and Hearing Disorders, 48, 114-118.

Stansfield, J. (1990). Prevalence of stuttering and cluttering in adults with mental handicaps. Journal of Mental Deficiency Research, 34, 287-307.

Steffelaar, J., and Evenhuis, H. (1989). Life expectancy, Down syndrome, and dementia, Lancet, 492-493.

Stoel-Gammon, C. (1980). Phonological analysis of four Down's syndrome children. Applied Psycholinguistics, 1, 31-48

Swetlik, B., and Brown, L. (1977). Teaching severely handicapped students to express selected first, second, and third person singular pronoun, responses in answer to "whodoing" question. In N. Haring and L. Brown (Eds.), Teaching the severely handicapped (vol.2, pp. 15-62). New York: Grune and Stratton.

Tulving, E. (1983). Elements of episodic memory. New York: Oxford University Press.

Van Borsel, J. (1988). An analysis of the speech of five Down's syndrome adolescents. Journal of Communication Disorders, 21, 409-422.

Van Borsel, J. (199l, August). Personal communication.

Van Borsel, J. (1993). De articulatie van adolescenten en volwassenen met het syndroom van Down. Unpublished doctoral dissertation, Vrije Universiteit van Brussel, Faculteit van Geneeskunde en Farmacie.

Yairi, E., and Clifton, N. (1972). Disfluent speech behaviour of preschool children, high school seniors and geriatric persons. Journal of Speech and Hearing Research, 15, 714719.

Willott, J. (1991). Aging and the auditory system: Anatomy, physiology and psychophysics. London: Whurr.

Yamada, J. (1990). Laura. A case for the modularity of language. Cambridge, MA: MIT Press.

Young, E., and Kramer, B. (1991). Characteristics of agerelated language decline in adults with Down syndrome. Mental Retardation, 29, 75-79.

Zisk, P., and Bialer, I. (1967). Speech and language problems in mongolism: A review of the literature. Journal of Speech and Hearing Disorders, 32, 228-241.

Address for correspondence:

Jean A. Rondal

Laboratoire de Psycholinguistique

Université de Liège

B-32 Sart Tilman

4000 Liège

Belgium 